of a suitable circumlunar transmitting or receiving satellite. Which of these approaches is most economical depends on a detailed assessment of ionosphere penetration of signals at the Earth terminal and of the effect of Earth atmospherics.

Because this evaluation will be long and involved, the results that can be expected from a basic satellite transmitter system will be outlined here as an example from which we can judge the information that is possible from this type of experiment. Reflected wave-lengths of metre size and greater indicate a smooth figure for the lunar surface as a whole 4 . The portion of the Moon which is transparent to radio waves should act as a spherical lens and therefore as a gigantic focusing antenna. If the index of refraction of the transparent lunar material for radio waves lies between $\mathbf{1 . 2 5}$ and 2 , as is true for light terrestrial rocks, then a satellite orbiting at a distance of between 300 miles and 50 miles above the lunar surface will produce a strongly focused beam from the Moon, which acts as a lens antenna. As the transmitting satellite passes behind the Moon from the Earth, this beam should pass across the surface of the Earth.

The strength of the central lobe of this beam will depend on the transmitter power and radiator gain, and on the degree of transparency and area of this lunar material. The angular size will depend on the relation between the satellite position and the ideal focal point of the Moon as a lens, as well as the relation between the lunar diameter and the wave-length. The relative angular size and phase of the side-lobe pattern will depend on the radial depth of the transparent layer and the transmitted frequency. Several passes, each transmitting a different frequency, or a time-sharing system between pulses of various frequencies to obtain data from several frequencies at a single pass, should produce data equivalent to an imagined X-raying of the Moon. Thus a small unmanned lunar satellite could be used as a vehicle to determine the feasibility of a miniature and simple system of trans. lunar voice communication, and at the same time could considerably increase our knowledge of the internal structure of the Moon. The cost of this effort would be quite small compared with the cost of a manned landing, and could contribute considerably to the safety and comfort of future lunar explorers.

$$
\text { Winfield W. Salisbury }
$$

Harvard College Observatory,

Smithsonian Astrophysical Observatory, Cambridge, Massachusetts.

'Salisbury, J. W., and Glaser, P. E., (eds.), The Lunar Surface Layer (Academie Press, New York, 1964).

${ }^{2}$ Urey, Harold C., "Age of the Moon, Chemical Composition, Geological Aspects, Stress and Cooling History", in Conf. Lunar Exploration, Bull. Virginia Polytech. Inst., 56, No. 7'(1963).

${ }^{s}$ Piddington, J. H., and Minnett, H. C., Austral. J. Sci. Res.,\$2, 63 (1949).

- Muhleman, D. O., dissert. Harvard Univ. (1964).

\section{Occurrence of Hydrogen Peroxide in Sea Water}

Traces of dissolved substances, of the order of $10^{-7} \mathrm{M}$ or less, can or may have far-reaching effects on the type or growth rate of organisms in the sea ${ }^{1}$. We now wish to report the occurrence of a possible ectocrine, hydrogen peroxide, in surface sea water samples taken near Port Aransas. We have no direct evidence suggesting that hydrogen peroxide in sea water has any biological or chemical significance; however, from continuing experiments on the growth of single cells of coccoid blue-green algae on agar plates ${ }^{2,3}$, we are led to propose that it could be a significant ecological variable.

Hydrogen peroxide was measured in sea water samples using the sensitive scopoletin-peroxidase fluorescence technique of Andreae ${ }^{4}$ and Perschke and Broda ${ }^{5}$. For the values reported here a stoichiometry of one part scopoletin. to one part hydrogen peroxide was used. Changes in fluorescence were detected with a barrier cell (IRC $A-10 M)$ and measured on a Keithley model $150 \mathrm{~A}$ microvolt-ammeter. (An American Instrument Co. photomultiplier microphotometer was used in later work.)

$\begin{array}{cc}\text { Table 1. Hydrogen Peroxide in SURfaCe Sea Water SAMPdes } \\ \text { Location } & \mu \text { g hydrogen peroxide/l. } \\ \text { Boat basin adjacent to Institute } & 1 \cdot 6,1 \cdot 6,2 \cdot 8 \\ \text { Tide pool near beach } & 0 \cdot 5,6 \cdot 7,2 \cdot 6 \\ \text { Beach near South jetty } & 5 \cdot 8,1 \cdot 0,4 \cdot 0 \\ \text { Open Gulf } & 5 \cdot 5,3 \cdot 3\end{array}$

For the first three samples: Date and weather conditions shown in order left to right: April 21, mostly cloudy, air temp. $27^{\circ} \mathrm{C}$; June 3, bright sun, air temp. $31^{\circ} \mathrm{C}$, south-easterly wind at $15-20$ m.p.h.; July 8 , bright sun, air temp. $31^{\circ} \mathrm{C}$, south-easterly wind at 20-22 m.p.h. Open Gulf samples: first sample June 11, 10 miles offshore, blue water, clear sky, south-easterly wind at 5-10 m.p.h.; second sample September 14,5 miles offshore, turbid water, clear sky, south-easterly wind at 12-15 m.p.h.

The sea water samples were collected in 'Pyrex' or plastic containers. They were assayed as soon as possible, usually within $30 \mathrm{~min}$. A typical assay consisted of the following: $6 \mathrm{ml}$. of sea water (unfiltered); $0.5 \mathrm{ml} .(1 \mu \mathrm{g})$ of scopoletin (Mann Laboratories); and $0.5 \mathrm{ml}$. of $0.08 \mathrm{M}$ tris buffer, $p \mathbf{H} 8 \cdot 0$. The initial fluorescence baseline was measured, then $0.05 \mathrm{ml} .(200 \mu \mathrm{g})$ peroxidase, Sigma Chemical Co., Type II, was added. The addition of catalase to samples of sea water which gave strongly positive assays of hydrogen peroxide resulted in complete loss of activity in the scopoletin-peroxidase system.

Table 1 shows some of the results found. Our experience so far would suggest that the presence of traces of hydrogen peroxide is a constant feature of sea water taken from the Port Aransas area.

We make no specification as to the source of the hydrogen peroxide. It could be formed photochemically in the atmosphere, photochemically in sea water itself through catalysis by dissolved pigments ${ }^{6}$ or possibly even through the metabolic activity of micro-organisms. The data so far do not allow a choice to be made from these possibilities. This work was supported by the National Science Foundation.

\section{Van BaAlen \\ J. E. MARLER}

Institute of Marine Science,

University of Texas,

Port Aransas, Texas.

'Lucas, C. F., in Oceanography, 499 (Amer. Assoc. Adv. Sci., Washington, D.C., 1961).

'Van Baalen, C., J. Phycol., 1, 19 (1965).

${ }^{3}$ Van Baalen, C., J. Phycol. (submitted).

4 Andreae, W. A., Nature, 175, 859 (1955).

Perschke, H., and Broda, E., Nature, 190, 257 (1961).

- Friedrich, H., in Oceanography, 257 (Amer. Assoc. Adv. Sci., Washington. D.C., 1961).

\section{Surface Tension of Slick Patches near Kelp Beds}

DURING a voyage off southern California near Santa Catalina Island some surface tension measurements were made on the open sea and over and around the slick areas associated with kelp beds. The usual methods of measuring surface tension involve laboratory equipment which is not feasible for use aboard a small sailing ship. For this reason, these tests were made with drops of a series of ten oil solutions, calibrated so that each solution would just spread against a different specific surface pressure, or lowering of surface tension. This calibrated series made it possible to measure, by inspection, surface tensions in the range $76-30$ dynes $/ \mathrm{cm}$.

Based on N. K. Adam's' technique, a series of solutions of a hydrophilic compound, $n$-dodecyl alcohol, and nonspreading oils was standardized so that a drop of each oil solution just spread against a measured surface tension. Solutions of known surface tensions, determined by a Du Nuoy tensiometer calibrated with distilled water, were 